\title{
Dynamic Analysis of the Traffic of Vehicles Used in Car Sharing
}

\author{
Sergey Sergeev \\ Graduate School of Service and Trade, \\ Institute of Industrial Management, Economics and Trade, \\ Peter the Great St. Petersburg Polytechnic University, Russia. \\ E-mail: sergeev2@yandex.ru \\ Svetlana Bozhuk \\ Graduate School of Service and Trade, \\ Institute of Industrial Management, Economics and Trade, \\ Peter the Great St. Petersburg Polytechnic University, Russia. \\ E-mail: bojuk.svetlana@yandex.ru \\ Natalia Pletneva \\ Graduate School of Service and Trade, \\ Institute of Industrial Management, Economics and Trade, \\ Peter the Great St. Petersburg Polytechnic University, Russia. \\ E-mail: gvozdok@yandex.ru

\section{Konstantin Evdokimov} \\ Science Research Center, Economics \& Law, \\ Belgorod University of Cooperation, Russia. \\ E-mail: ekvmanager@mail.ru

\section{Yury Klochkov} \\ SPBPU Advanced Manufacturing Technologies Center of the National Technology Initiative, \\ Peter the Great St. Petersburg Polytechnic University, Russia. \\ Corresponding author: y.kloch@gmail.com
}

(Received on September 11, 2020; Accepted on March 25, 2021)

\begin{abstract}
During digitalization of transport service segment people use modern facilities such as geolocation, M2M connectivity, online payments, customer identification. We can also see a high competition here. The task of car sharing managers is to search for the optimal methods of doing business. As the regulations of business, ecological standards and technology environment of the main players is almost similar because of using the same mobile and cloud resources, it is possible to get a competitive advantage by the development of mobile apps for the employee's PCs and smartphones of customers. The math model shown in this article is developed for implementing in digital platforms of such kind of business. This gives the opportunity to offer customers more attractive car sharing services and to reduce costs by following the environmental restrictions at the same time.
\end{abstract}

Keywords- Ecology, Sustainable development, Traffic, Digital technologies, Mobile applications, Megalopolis, Electric car, Car sharing.

\section{Introduction}

The global growth trend of urban agglomerations is primarily determined by their role in the global economic system (Zhgulev et al., 2018). The megacities Alpha and Alpha + of the GaWC 
(Globalization and World Cities) rating (Bozhuk and Pletneva, 2017) will keep key importance for many more decades. One of the most difficult problems for the population of such cities is a sharp deterioration of environment. At the same time, the share of automobile traffic in the adverse environmental impact in industrial centers reaches $70 \%$. We note that in addition to chemical poisoning, transport is also a source of mechanical, noise and secondary pollution. The largest proportion of toxic substances arises from engine exhaust gas. More efforts should be made to further reduce $\mathrm{CO} 2$ concentration in the cities (Nuzzolo et al., 2018; Yang et al., 2020).

One of the ways to solve this problem is to reduce the use of internal combustion engines, replacing them with electric ones.

In Moscow and Saint-Petersburg the perspectives in disseminating environmentally friendly personal transport are the most realistic in comparison with the regions. In Saint-Petersburg from January 1, 2018 until January 1, 2020 the transport tax on electric vehicles with a capacity up to $150 \mathrm{hp}$ has been abolished, the equivalent of electric vehicles is $110 \mathrm{~kW}$. This amendment was adopted by the Legislative Assembly of Saint-Petersburg on June 23, 2016 (https://www.gov.spb.ru/gov/otras1/tr_infr_kom/news/90078/).

In the same 2016 according to the Decree of the Government of Saint-Petersburg No. 417, the owners of electric vehicle are allowed to park their vehicles on intercepting and city parking areas free of charge upon the presentation of an original or a notarized copy of a vehicle passport containing the indication of a type of engine. In addition, electric cars can be placed free of charge in the paid parking zone if there is an appropriate parking permit (https://elmobil.ru/v-sanktpetersburge-otmenen-transport/). However, the number of people wishing to purchase electric vehicles in a metropolis is still small.

On the other-hand there is a negative tendency of cutting down state funds to reduce negative manmade impact of environment (according to the Federal State Statistics Service's data) (Figure 1).

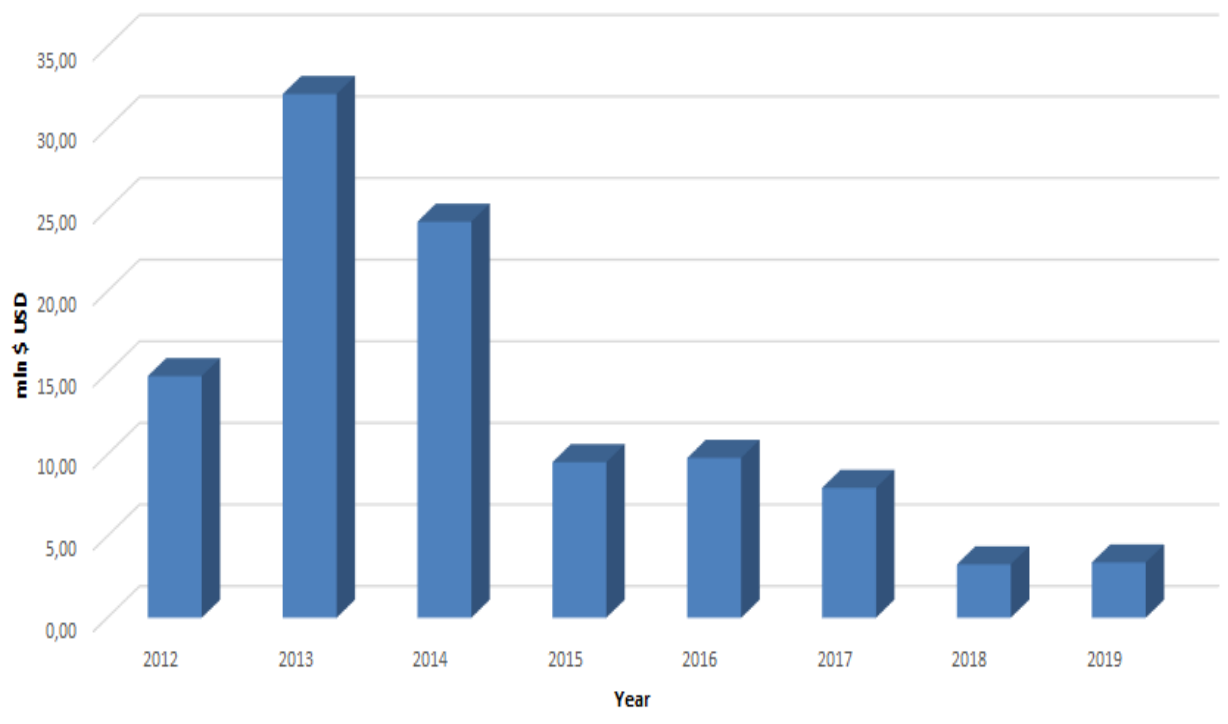

Figure 1. The research costs to reduce negative man-made impact of environment. 
International Journal of Mathematical, Engineering and Management Sciences

Vol. 6, No. 3, 847-859, 2021

https://doi.org/10.33889/IJMEMS.2021.6.3.050

The socio-economic role of transport is exceptional and even a partial refusal to use traditional cars requires an alternative. First of all, the main condition is to meet the needs of citizens both on trips and in the provision of infrastructure of a metropolis with a full set of goods and cargoes. At the same time, it is known that an ordinary resident uses his car for short trips and private transport is a hindrance to traffic more than $90 \%$ of the time (Bozhuk et al., 2019; Engdahl et al., 2017). Key performance indicators of transportation companies (Table 1).

Table 1. Automobile transportation services for cargo and passenger carriage performed by organizations in St. Petersburg in 2019.

\begin{tabular}{|l|c|c|}
\hline \multicolumn{1}{|c|}{ Indicator } & Total & 2018 percentage \\
\hline Cargo, thous.ton & 4429 & 67,1 \\
\hline Cargo turnover, mln.tonne-km & 2178 & 83,1 \\
\hline Passengers, million & 579 & 99,1 \\
\hline Passenger turnover, million Passenger-km & 3455 & 101,9 \\
\hline
\end{tabular}

The volume of commercial transportation by different types of organizations without small businesses in 2019 was 10.2 million tons and increased by $11.4 \%$ compared to 2018 , cargo turnover was 6214.3 million tons-km and increased 2.1 times (Table 2).

Table 2. Passenger commercial transportation.

\begin{tabular}{|l|c|c|}
\hline \multicolumn{1}{|c|}{ Indicator } & January- March 2020 & percentage to the same period 2019 \\
\hline Passenger transported, million & 135,8 & 95,6 \\
\hline Passenger turnover, million. Passenger-km & 804,9 & 98,7 \\
\hline
\end{tabular}

According to Avtostat agency as of July 1, 20191.77 million cars were registered in St. Petersburg, and 0.5 million in the Leningrad Region. The number of people that received driving licenses in 2019 was 40827 (Table 3).

The search for a solution that respects the balance of economic efficiency, meets the needs for transportation of people and goods, has the priority of environmental accounting, has led to the car sharing paradigm in the categories $\mathrm{M}$ (passenger vehicles with not less than 4 wheels) $\mathrm{N}$ (cargo cars) This type of niche service in Europe and in Japan is effectively used in B2C (Business-tocustomer) and P2P (person-to-person / peer-to-peer) segments and shows a decrease in traffic and pollution level. Car sharing has been proven to remarkably contribute to easing energy and environment crises (Kireeva et al., 2019; Polteva et al., 2019; Shoshany Tavory et al., 2020).

The most dynamic car sharing, in contrast to an ordinary rent, is developing due to digital technology (Borisoglebskaya and Sergeev, 2018). The basic conditions for the development of the SIM (Subscriber Identification Module) solutions segment were created after the widespread penetration of $4 \mathrm{G}$ mobile networks, the mass distribution of smartphones with GPS / GLONASS functions, Internet banking linked to an identified user. KESS systems (Konfigurierbares elektronisches Schadensi dentifikations system - Configurable Electronic Damage Identification System) are also being developed, as well as Voyager solutions that enable the connection of additional equipment, for example, fuel flow and fuel level sensor, dispatch communication, alarm button and other services based on SIM technologies. 
International Journal of Mathematical, Engineering and Management Sciences

Vol. 6, No. 3, 847-859, 2021

https://doi.org/10.33889/IJMEMS.2021.6.3.050

Table 3. Diagram. basic car statistics in St. Petersburg.

\begin{tabular}{|c|c|c|c|c|c|c|c|c|}
\hline \multirow{5}{*}{ 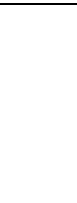 } & \multirow{5}{*}{\multicolumn{2}{|c|}{ Cars (M1) }} & \multirow{3}{*}{ Code } & \multirow{3}{*}{$\begin{array}{c}\text { Total } \\
\text { vehicles }\end{array}$} & \multicolumn{4}{|c|}{ Owned by } \\
\hline & & & & & \multirow{2}{*}{ individuals } & \multirow{2}{*}{ companies } & \multicolumn{2}{|c|}{ property } \\
\hline & & & & & & & state & foreign \\
\hline & & & B & 1 & 2 & 4 & 5 & 6 \\
\hline & & & 1 & $\begin{array}{c}1744 \\
133 \\
\end{array}$ & 1637747 & 106386 & 8524 & 160 \\
\hline \multirow{21}{*}{ હ્. } & \multicolumn{2}{|c|}{ Emission class 0} & 2 & 1195 & 1161 & 34 & 6 & 0 \\
\hline & \multicolumn{2}{|c|}{ Emission class 1} & 3 & 83 & 81 & 2 & 0 & 0 \\
\hline & \multicolumn{2}{|c|}{ Emission class 2} & 4 & 13315 & 12750 & 565 & 216 & 0 \\
\hline & \multicolumn{2}{|c|}{ Emission class 3} & 5 & 45693 & 43183 & 2510 & 567 & 3 \\
\hline & \multicolumn{2}{|c|}{ Emission class 4} & 6 & 315755 & 304449 & 11306 & 1314 & 23 \\
\hline & \multicolumn{2}{|c|}{ Emission class 5} & 7 & 78554 & 70116 & 8438 & 220 & 13 \\
\hline & \multicolumn{2}{|c|}{ Emission class 6} & 8 & 5 & 4 & 1 & 0 & 1 \\
\hline & \multicolumn{2}{|c|}{ Emission class not defined } & 9 & $\begin{array}{c}1289 \\
533\end{array}$ & 1206003 & 83530 & 6201 & 120 \\
\hline & \multicolumn{2}{|c|}{ Foreign made vehicles } & 10 & $\begin{array}{c}1441 \\
283\end{array}$ & 1349799 & 91484 & 5799 & 160 \\
\hline & \multirow{6}{*}{ 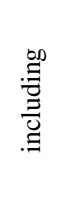 } & less than 1 year old & 11 & 78560 & 62083 & 16477 & 298 & 5 \\
\hline & & $1-3$ years old & 12 & 187282 & 158498 & 28784 & 911 & 45 \\
\hline & & $3-5$ years old & 13 & 140677 & 126337 & 14340 & 725 & 34 \\
\hline & & $5-10$ years old & 14 & 502613 & 481147 & 21466 & 2306 & 61 \\
\hline & & $10-15$ years old & 15 & 295589 & 289268 & 6321 & 1387 & 14 \\
\hline & & more than 15 years old & 16 & 236562 & 232466 & 4096 & 172 & 1 \\
\hline & \multicolumn{2}{|c|}{\begin{tabular}{|l|} 
less than 1 year old \\
\end{tabular}} & 17 & 81725 & 64662 & 17063 & 334 & 5 \\
\hline & \multicolumn{2}{|c|}{ 1-3 years old } & 18 & 194772 & 164692 & 30080 & 1114 & 45 \\
\hline & \multicolumn{2}{|c|}{ 3-5 years old } & 19 & 148372 & 132997 & 15375 & 980 & 34 \\
\hline & \multicolumn{2}{|c|}{ 5-10 years old } & 20 & 524986 & 500800 & 24186 & 3491 & 61 \\
\hline & \multicolumn{2}{|c|}{$10-15$ years old } & 21 & 325624 & 317160 & 8464 & 2395 & 14 \\
\hline & \multicolumn{2}{|c|}{ more than 15 years old } & 22 & 468654 & 457436 & 11218 & 210 & 1 \\
\hline \multicolumn{3}{|c|}{ Vehicles using natural gas as fuel } & 23 & 1715 & 1135 & 580 & 0 & 0 \\
\hline 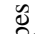 & \multicolumn{2}{|c|}{ compressed natural gas } & 24 & 1499 & 922 & 577 & 0 & 0 \\
\hline 至 & \multicolumn{2}{|c|}{ Liquefyied natural gas } & 25 & 216 & 213 & 3 & 0 & 0 \\
\hline \multicolumn{3}{|c|}{ Vehicles using liquefied petroleum gas as fuel } & 26 & 3792 & 2896 & 896 & 6 & 0 \\
\hline Veh & les u & ing electric motors & 27 & 169 & 155 & 14 & 0 & 0 \\
\hline
\end{tabular}

\section{Methods of Research}

In order to automate management decisions in the field of environmental performance of urban transport the structure of a digital city should include the aggregators for collecting statistical information, the concentration in cloud services with a possibility of its further computer processing and exchange with SIM solutions terminals.

The mathematical model presented in this work (Borisoglebskaya and Sergeev, 2018). enables us to carry out a dynamic analysis (Krasnov et al., 2017) of the traffic of vehicles used in a car sharing.

In the work of a manager of a car-sharing company decision-making should be based on the balanced calculation, therefore, for these purposes it is required to build a mathematical model that takes into account: stochastic nature of the data on the routes of use of cars provided by the service. dependence on the days of the week and seasonality factor, linking to economic indicators since the result of taken decisions should be profit maximization.

We introduce a series of formalisms. From the statistics accumulated on the server of a car sharing dispatching system, we obtain data on the number of cars movements within the service coverage area (Akyelken et al., 2018; Ceccato and Diana, 2018; Parfenova et al. 2019). After aggregating 
International Journal of Mathematical, Engineering and Management Sciences

Vol. 6, No. 3, 847-859, 2021

https://doi.org/10.33889/IJMEMS.2021.6.3.050

the data, we can get a set of probabilities of using transport from point to point. Let us reduce this data into the matrix of transition probabilities $P=\left\|p_{i j}\right\|$. Next, we define a set of relevant economic indicators reflecting the route from $i$ to $j$. Let us denote the numerical value in monetary terms by $r_{i j}$. In practice, these values are equal to the profit from using a vehicle on a route minus the costs of insurance, depreciation, maintenance and also the lost profits because of the fact that the probability of rent is low at the final destination point and you will need to move a vehicle to a demand zone or provide rent at a discount. Thus, the indicators $r_{i j}$ can take both positive and negative values. Since a car sharing company is obliged to provide its services throughout the territory, possible negative profit values should be covered by the revenue from other routes.

The matrix also includes the probabilities of accidents and possible technical malfunctions related to minor repairs (locks repairing, replacement of batteries, blown lamps and batteries in key chains, etc.).

To determine the values of the total revenue from each car on a certain planning horizon, it is necessary to describe its work using a mathematical model. To do this let us divide the planned interval into $n$ parts, for example, the average number of trips during the day. Let's start the calculation from point 1 .

Then with a probability $p_{1 j}$ the profit will be $r_{i j}$ for any of possible final destination points $j$. Consequently, the possible profit is equal to $\sum_{j} p_{1 j} r_{1 j}$ for the first trip from the planned interval. In addition, after arriving at the point $j$ a car will continue to be used and it is necessary to take into account the remaining profit until the end of the total planning period.

For this let us introduce the following notation: $v_{1}(n)$ is the total profit for $n$ trips, respectively, $v_{1}(n-1)$ is the profit for the trips $n-1$ remaining until the end of planned period.

Let us write the formalized ratio: $v_{1}(n)=\sum_{j} p_{1 j}\left[r_{1 j}+v_{1}(n-1)\right]$. Since the initial point of operation can be arbitrary, then, having carried out similar reasoning, we can write the expression for profit in general: $v_{i}(n)=\sum_{j} p_{i j}\left[r_{i j}+v_{i}(n-1)\right]$ at $\forall i$. Now you can introduce the vector $\bar{V}(n)$ whose components are calculated as a set of values: $\bar{V}(n)=\left[v_{1}(n), v_{2}(n), \ldots, v_{j}(n) \ldots\right]$ into a model and reduce the calculation to the vector ratio:

$\bar{V}(n)=\bar{Q}+\bar{V}(n-1)$

here the vector $\bar{Q}$ is the diagonal of the matrix obtained by the product of the matrix of the probabilities of moving vehicles $p_{i j}$ to transpose of the matrix composed of the corresponding profit values $r_{i j}$. The resulting expression (1) is a recurrence formula that is convenient for computer programming. In this case, instead of the sequence $\bar{V}(1)=\bar{Q} ; \quad \bar{V}(2)=\bar{Q}+P * \bar{V}(1)$; 
International Journal of Mathematical, Engineering and Management Sciences

Vol. 6, No. 3, 847-859, 2021

https://doi.org/10.33889/IJMEMS.2021.6.3.050

$\bar{V}(3)=\bar{Q}+P * \bar{V}(2) ; \bar{V}(n)=\bar{Q}+P * \bar{V}(n-1)$ you can calculate only $\bar{Q}$ and the set of powers of the matrix $P$. Then the required value is calculated as: $\bar{V}(n)=\bar{Q}\left[E+\sum_{k=1}^{n} P^{k}\right]$, where $E$ is the identity matrix.

\section{Results}

Testing of the presented mathematical model was carried out using data from Uber services as the most advanced digital platform.

The Uber service conditionally divided the territory of Saint Petersburg into a number of zones: sleeping areas, business and educational centers, industrial centers, recreational facilities, transportation hubs, exit boundaries to the nearest suburbs (Figure 2).

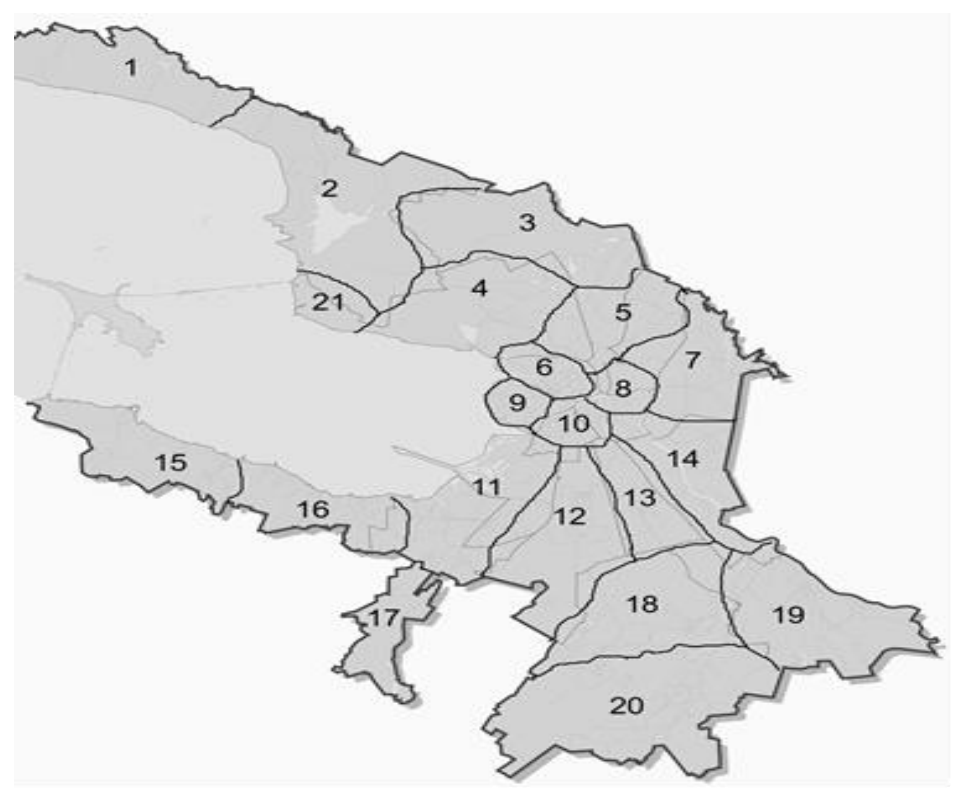

Figure 2. The division of Saint Petersburg into zones based on the differentiation of the offers of Uber service.

Moreover, there can be several zones of each type for the present case depending on the geolocation and the data of Uber aggregator, they are shown in Table 4.

Table 4. Symbols for the types of zone on the basis of the differentiation of the offers of Uber service.

\begin{tabular}{|l|c|}
\hline Points & Number on the map \\
\hline sleeping quarters & $2,16,18,19$ \\
\hline business and educational centers & $6,10,11,13$, \\
\hline industrial centers & $4,8,12,17$ \\
\hline recreational facilities & $3,7,21$ \\
\hline transport hubs & $5,9,14$ \\
\hline boundaries of departure into the nearest suburbs & $1,15,20$, \\
\hline
\end{tabular}


Based on the statistics of Uber calls, not only to taxi services, but also such as UberWAV, UberPIZZA, UberEATS which need to minimize the tracks, the matrix of transition probabilities is formed: $P=\left\|p_{i j}\right\|^{N, N}$. Here $N$ is the number of zones of division of the city, $p_{i j}$ is the probability of moving from the zone $i$ to the zone $j$, for $i, j=1, \ldots, N$. We also know the value $\mathrm{G}-$ the total number of car sharing cars. Obviously, the condition is met: $\sum_{j=1}^{N} p_{i j}=1 ; i=1, \ldots, N$, since the matrix $P$ is stochastic on the right, reflecting the full group of events. Next, consider the initial point of time when the distribution of vehicles obeys the stochastic vector $\bar{Q}^{T}(0)=\left(q_{1}(0), \ldots, q_{k}(0), \ldots, q_{n}(0)\right)$, under the condition $\sum_{k=1}^{n} q_{k}(0)=1$. Extrapolating to the planned horizon the situation in the city with a certain discrete time $\Delta t$, we can write the following expression for any moment: $t: q_{k}(t+\Delta t)=\sum_{i=1}^{N} q_{i}(t) p_{i k}$. Then using formula (1) we make calculations, which show that with changing the time the process converges to the limiting vector $\bar{Q}^{*}$. Then, knowing the expected value $m_{i}$ of the needs of each zone $i=1, \ldots, N$ in transport units, one can calculate (Iliashenko et al., 2018) the necessary number of vehicles from the condition $G \times q_{i}^{*} \geq m_{i}$.

As an example, let us consider the calculation on the matrix (Bozhuk et al., 2019) of transition probabilities $P$ of a small dimension $3 \times 3$ for data on one sleeping area, one business center and a transport node:

$$
P=\left|\begin{array}{lll}
0.68 & 0.18 & 0.14 \\
0.24 & 0.15 & 0.61 \\
0.17 & 0.35 & 0.48
\end{array}\right|
$$

Let us define $\bar{Q}_{3}=\left(q_{s}, q_{b}, q_{t}\right)$ a probability vector of distributing car sharing cars along three mentioned areas, where: $q_{s}$ is a probability of being in sleeping area; $q_{b}$ is a probability of being in business center; $q_{t}$ is a probability of being in transport node.

While using above mentioned formulas we will get the following results are shown in Table 5.

Table 5. Calculation process.

\begin{tabular}{|c|c|c|}
\hline$q_{s}$ & $q_{b}$ & $q_{t}$ \\
\hline 0,68 & 0,18 & 0,14 \\
\hline 0,529 & 0,198 & 0,272 \\
\hline 0,454 & 0,220 & 0,326 \\
\hline 0,417 & 0,229 & 0,354 \\
\hline 0,399 & 0,233 & 0,368 \\
\hline 0,390 & 0,236 & 0,375 \\
\hline 0,385 & 0,237 & 0,378 \\
\hline 0,383 & 0,237 & 0,380 \\
\hline 0,382 & 0,237 & 0,381 \\
\hline
\end{tabular}


International Journal of Mathematical, Engineering and Management Sciences

Vol. 6, No. 3, 847-859, 2021

https://doi.org/10.33889/IJMEMS.2021.6.3.050

Computer calculations showed rapid convergence to the stationary solution:

$\bar{Q}^{* T}=(0.382 ; 0.237 ; 0.381)$.

This is quite important, as it helps to estimate the necessity of exact number of car sharing cars in different areas of the city.

Since the dimension of matrices does not matter for computer programming (Provotorov et al., 2019), the corresponding calculations should be carried out using the maximum possible number $N$ of separate zones of the city. The smaller the size of fragmentation zones is the more accurate forecast results will be. In this study the limitations were the source data obtained from the Uber services, where there are only $N=21$. However, when analyzing the data sets for geo-referenced queries, it becomes possible to obtain a more perfect differentiation of the territory as well as a refined matrix of transition probabilities. As an additional result, from the forecast of the distribution of transport, you can get recommendations for the managers of a car sharing company to reconfigure transport during the night period to optimize profits (Aytasova et al., 2019; Wang et al., 2020).

You can also apply the obtained results for mobile transport refueling that eliminates excess mileage and reduces environmental pollution.

\section{Discussion}

At the beginning of 2019, there were eight car-sharing companies in Saint Petersburg. The city officials have a great hope for this alternative to other types of transport. The cost of a minute of using a car-sharing car ranges from nine to 14 US cents, depending on a chosen company. According to statistics, one car per day can meet the needs of 10 drivers. These facts indicate a high chance of spreading car sharing in megalopolises (Boldrini et al., 2016).

At the same time, by virtue of its novelty, the development of car sharing remains highly debatable. The participants of the discussion, first of all, drew attention to an irresponsible attitude of consumers towards rented cars. One of the problems is the impunity of leaving car sharing cars in the wrong place, which makes it difficult for other cars to leave. In addition, during the discussion, attention was drawn to the possibility of using a rented car in criminal and illegal commercial activities.

As ideas for improving the development of car sharing, it was proposed to introduce uniform requirements for car users for all car sharing companies (length of service, strict regulation of parking spaces, etc.). The focus should be on the development of mobile digital technologies in car sharing. It seems that the development of car sharing may be one of the realistic alternatives for solving the environmental problems of a metropolis (Ahmad et al., 2019; Masloya et al., 2020).

Promoting cost effective car share systems requires reduction of costs associated to crashes and insurance. To achieve this goal, it is imperative to characterize car share users involved in crashes and understand factors that can explain at-fault and not-at fault drivers (Stan et al., 2019; Viviani, 2016). Therefore, we will analyze the car sharing statistics. The average percentage of car accidents involving car sharing was $2.57 \%$ in 2019 (Table 6, Figure 3, Table 7). 
International Journal of Mathematical, Engineering and Management Sciences

Vol. 6, No. 3, 847-859, 2021

https://doi.org/10.33889/IJMEMS.2021.6.3.050

Table 6. Number of car accidents in 2019.

\begin{tabular}{|c|c|c|}
\hline Month & Total car accidents & Car sharing accidents \\
\hline January & 423 & 13 \\
\hline February & 383 & 11 \\
\hline March & 515 & 11 \\
\hline April & 513 & 12 \\
\hline May & 577 & 8 \\
\hline June & 565 & 11 \\
\hline July & 570 & 21 \\
\hline August & 615 & 20 \\
\hline September & 606 & 14 \\
\hline October & 555 & 15 \\
\hline
\end{tabular}

The fleet of car sharing in 2019 numbers about 3 thousand cars.

Table 7. Traffic violations statistics in St. Petersburg in 2019.

\begin{tabular}{|c|c|c|c|c|c|c|c|c|c|c|}
\hline & & \multirow[b]{2}{*}{ Code } & \multirow[b]{2}{*}{$\begin{array}{c}\text { Traffic } \\
\text { violations }\end{array}$} & \multirow{2}{*}{$\begin{array}{c}\text { Procedeengs } \\
\text { for } \\
\text { administrative } \\
\text { offences }\end{array}$} & \multicolumn{4}{|c|}{ Police orders } & \multirow{2}{*}{$\begin{array}{c}\text { Administrative } \\
\text { penalty } \\
\text { executed. } \\
\text { (USD) }\end{array}$} & \multirow[b]{2}{*}{$\begin{array}{c}\text { issued in } \\
2019 \text { (USD) }\end{array}$} \\
\hline & & & & & Warning & $\begin{array}{c}\text { Dismissal } \\
\text { order }\end{array}$ & $\begin{array}{c}\text { Administrative } \\
\text { penalty }\end{array}$ & $\begin{array}{l}\text { column 5, } \\
\text { amount } \\
\text { (USD) }\end{array}$ & & \\
\hline & $\mathrm{A}$ & $\mathrm{B}$ & 1 & 2 & 3 & 4 & 5 & 6 & 7 & 8 \\
\hline \multicolumn{2}{|l|}{ Total } & 1 & 3349096 & 3379599 & 3759 & 9324 & 3337131 & 37341588,14 & 27755244,86 & 25352726,71 \\
\hline \multirow{7}{*}{ types } & Drivers & 2 & 281374 & 310062 & 536 & 7634 & 301892 & 9013316,85 & 8430681,29 & 6919017,46 \\
\hline & $\begin{array}{l}\text { Owners of } \\
\text { vehicles } \\
\text { (based on } \\
\text { traffic } \\
\text { violation } \\
\text { auto } \\
\text { commit) }\end{array}$ & 6 & 2984550 & 2984550 & 0 & 0 & 2984550 & 26992152,02 & 18358952,57 & 17683037,23 \\
\hline & $\begin{array}{l}\begin{array}{l}\text { Public } \\
\text { officials }\end{array} \\
\end{array}$ & 7 & 1418 & 2468 & 25 & 171 & 2123 & 279854,78 & 225722,23 & 181863,12 \\
\hline & Companies & 8 & 525 & 874 & 52 & 162 & 658 & 557763,02 & 298825,89 & 200308,98 \\
\hline & Pedestrians & 9 & 52244 & 52364 & 3084 & 15 & 38528 & 298470,57 & 265441,06 & 195674,34 \\
\hline & Passengers & 10 & 2269 & 2355 & 62 & 5 & 2288 & 18337,71 & 14691,80 & 12235,44 \\
\hline & $\begin{array}{l}\text { others } \\
\text { (bikers, } \\
\text { carters } \\
\text { packers) }\end{array}$ & 11 & 1 & 6 & 0 & 0 & 6 & 92,69 & 46,35 & 30,90 \\
\hline
\end{tabular}


International Journal of Mathematical, Engineering and Management Sciences

Vol. 6, No. 3, 847-859, 2021

https://doi.org/10.33889/IJMEMS.2021.6.3.050

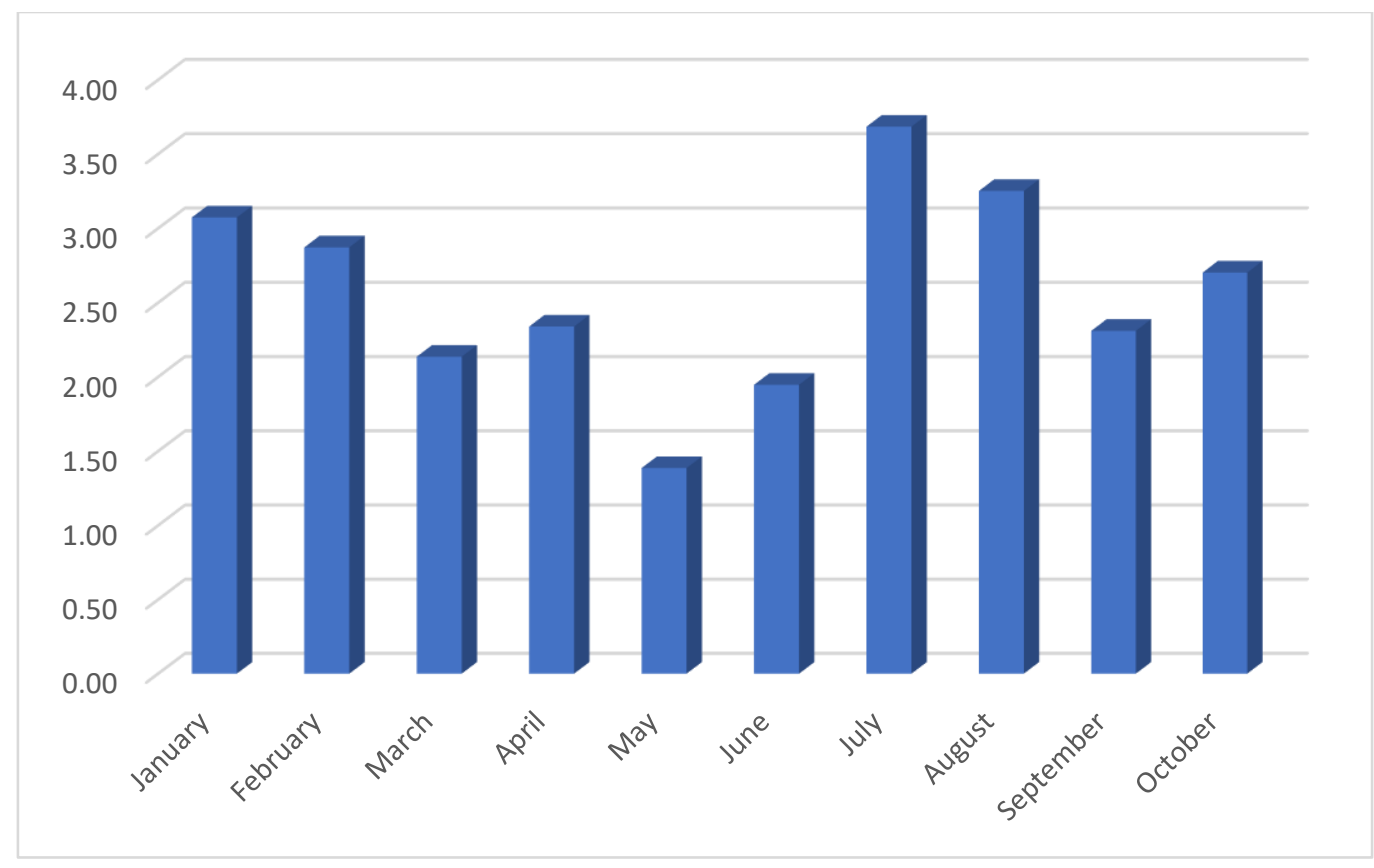

Figure 3. Diagram. Car sharing accidents percentage.

\section{Conclusion}

The digital solutions used in car sharing belong to the most advanced category of SIM Solutions (Subscriber Identification Module) (Krasnov at al., 2019). This mobile service includes full technical, electronic, financial and payment components, geolocation processing as well as advanced CRM system (Customer Relationship Management).

The improvement of environmental situation in a megacity is achieved not by reducing the total number of cars, but by reducing sharply traffic intensity and, first of all, by reducing the time period of vehicles staying in traffic jams with running engines.

The use of car sharing will lead to get parked cars off the street, which will increase the carrying capacity of highways. The danger of moving around the city on bicycles will be reduced. The experience of the Scandinavian and Baltic countries with a similar climate showed a positive effect of $b$ / $b$ trend (biking / blading) on the quality of life after a partial rejection of citizens from cars when traveling around the city.

To optimize the ratio of the number of vehicles used, provided that the population's needs are met and environmental damage is minimized, a scientifically based calculation is needed (Sergeev et al., 2019) using mathematical models of stochastic processes and numerical optimization methods.

It is necessary to develop administrative and legal measures to create the conditions for the development of such modern services based on the most advanced digital technologies that affect the interests of the entire population that, in addition to economic benefits, will have a significant social effect. 
International Journal of Mathematical, Engineering and Management Sciences

Vol. 6, No. 3, 847-859, 2021

https://doi.org/10.33889/IJMEMS.2021.6.3.050

On 24 April 2020, the Russian President declared the need to vote USD 38, 62 million for a grace period for car sharing leasing program realization. The Head of State made the statement at the government session to support the car industry in the face of COVID-19 pandemic.

\section{Conflict of Interest}

The authors confirm that there is no conflict of interest to declare for this publication.

Acknowledgment

The research is funded by Peter the Great St. Petersburg Polytechnic University.

\section{References}

Ahmad, S., Malik, S., Park, D.H., \& Kim, D. (2019). Design of lightweight driver-assistance system for safe driving in electric vehicles. Sensors, 19(21), 4761.

Akyelken, N., Givoni, M., Salo, M., Plepys, A., Judl, J., Anderton, K., Koskela, S. (2018). The importance of institutions and policy settings for car sharing-evidence from the UK, Israel, Sweden and Finland. European Journal of Transport and Infrastructure Research, 18(4), 340-359.

Aytasova, A., Selezneva, Z., Belinskaia, I., \& Evdokimov, K. (2019). Development of the process map "research and development" for agricultural organizations. In 2019 IOP Conference Series: Materials Science and Engineering (Vol. 666, No. 1, pp. 012072). IOP Publishing. St Petersburg, Russian Federation.

Boldrini, C., Bruno, R., \& Conti, M. (2016). Characterising demand and usage patterns in a large stationbased car sharing system. In 2016 IEEE Conference on Computer Communications Workshops (INFOCOM WKSPS) (pp. 572-577). IEEE. San Francisco, CA, USA.

Borisoglebskaya, L.N., \& Sergeev, S.M. (2018). Model of assessment of the degree of interest in business interaction with the university. Journal of Applied Economic Sciences, 12(8), 2423-2448.

Bozhuk, S., \& Pletneva, N.Y. (2017). The problems of market orientation of Russian innovative products (electric cars as a case study). In International Scientific Conference Energy Management of Municipal Transportation Facilities and Transport (pp. 1234-1242). Springer, Cham.

Bozhuk, S., Krasnostavskaia, N., Maslova, T., Pletneva, N. (2019). The problems of innovative merchandise trade in the context of digital environment. In 2018 IOP Conference Series: Materials Science and Engineering. (Vol. 497, No. 1, pp. 012115). IOP Publishing. St Petersburg, Russian Federation.

Bozhuk, S.G., Maslova, T.D., Pletneva, N.A., \& Evdokimov, K.V. (2019). Improvement of the consumers' satisfaction research technology in the digital environment. In IOP Conference Series: Materials Science and Engineering (Vol. 666, No. 1, p. 012055). IOP publishing. Saint-Petersburg, Russian Federation.

Ceccato, R., \& Diana, M. (2018). Substitution and complementarity patterns between traditional transport means and car sharing: a person and trip level analysis. Transportation, pp. 1-18. https://doi.org/10.1007/s11116-018-9901-8.

Engdahl, H., Englund, C., Habibi, S., Pettersson, S., Sprei, F., Voronov, A., \& Wedlin, J. (2017). Statistical data for free-floating car sharing versus public transport. In 30th International Electric Vehicle Symposium and Exhibition EVS 2017. Landesmesse Stuttgart Stuttgart, Germany.

https://elmobil.ru/v-sankt-petersburge-otmenen-transport/. (accessed 15.06.2019).

https://www.gov.spb.ru/gov/otrasl/tr_infr_kom/news/90078/ (Accessed 15.07.2018). 
International Journal of Mathematical, Engineering and Management Sciences

Vol. 6, No. 3, 847-859, 2021

https://doi.org/10.33889/IJMEMS.2021.6.3.050

Iliashenko, O., Krasnov, S., \& Sergeev, S. (2018). Calculation of high-rise construction limitations for nonresident housing fund in megacities. In E3S Web of Conferences (vol. 33, p. 03006). EDP Sciences. Samara, Russia.

Kireeva, N., Pozdnyak, I., \& Gazizulina, A. (2019). Filling a knowledge base for expert system in information security. In IOP Conference Series: Materials Science and Engineering (Vol. 618, No. 1, p. 012085). IOP Publishing. Saint-Petersburg, Russian Federation.

Krasnov S., Sergeev, S., Titov, A., \& Zotova, Y. (2019). Modelling of digital communication surfaces for products and services promotion. In 2019 IOP Conference Series: Material Science and Engineering (Vol. 497, p. 012032). IOP publishing. Saint-Petersburg, Russian Federation.

Krasnov, S.V., Sergeev, S.M., Mukhanova, N.V., \& Grushkin, A.N. (2017). Methodical forming business competencies for private label. In 2017 6th International Conference on Reliability, Infocom Technologies and Optimization (Trends and Future Directions) ICRITO (pp. 553-558). IEEE. Noida, India.

Maslova, T., Pletneva, N., Althonayan, A., Tarasova, E., \& Krasnov, A. (2020). Transformation of consumer behavior in the tourism industry in the conditions of digital economy. In IOP Conference Series: Material Science and Engineering (Vol. 940, p. 01207). IOP publishing. Saint-Petersburg, Russian Federation.

Nuzzolo, A., Persia, L., Comi, A., \& Polimeni, A. (2018). Shared autonomous electrical vehicles and urban mobility: a vision for Rome in 2035. In The 4th Conference on Sustainable Urban Mobility (pp. 772779). Springer, Cham.

Parfenova, V.E., Bulgakova, G.G., Amagaeva, Y.V., \& Evdokimov, K.V. (2019). Fuzzy modelling for tasks of management of the agricultural-industrial complex. In IOP Conference Series: Materials Science and Engineering (Vol. 666, No. 1, p. 012067). IOP Publishing. Saint-Petersburg, Russian Federation.

Polteva, T., Antipov, D., \& Klassen, N. (2019). The improvement of the market risk management mechanism at the automotive industry enterprises. In 2019 Amity International Conference on Artificial Intelligence, AICAI (pp. 1005-1014). IEEE. Dubai, United Arab Emirates.

Provotorov, V.V., Sergeev, S.M., \& Part, A.A. (2019). Solvability of hyperbolic systems with distributed parameters on the graph in the weak formulation. Vestnik of Saint Petersburg University. Applied Mathematics. Computer Science. Control Processes, 14(1), 107-117.

Sergeev, S., Kirillova, T., \& Krasyuk, I. (2019). Modelling of sustainable development of megacities under limited resources. In E3S Web of Conferences (Vol. 91, p. 05007). EDP Sciences. Moscow, Russia.

Shoshany Tavory, S., Trop, T., \& Shiftan, Y. (2020). Self-organized ridesharing: multiperspective annotated review. International Journal of Sustainable Transportation, 14(4), 270-279.

Stan, I., Suciu, V., \& Potolea, R. (2019). Smart driving methodology for connected cars. In $201923 \mathrm{rd}$ International Conference on System Theory, Control and Computing, ICSTCC (pp. 608-613). IEEE. Sinaia, Romania.

Viviani, M. (2016). How carsharing opens the way to smart electric mobility: success \& hurdles of the largest electric carsharing fleet in Canada. In 29th International Electric Vehicle Symposium 2016 EVS29 (pp. 500-505). Montreal, Canada.

Wang, G., Makino, K., Harmandayan, A., \& Wu, X. (2020). Eco-driving behaviors of electric vehicle users: a survey study. Transportation Research Part D: Transport and Environment, 78, 102188.

Yang, N., Li, Y., Liu, T., Wang, J., \& Zhao, H. (2020). Analysis of fatal factors influencing accidents involving two-wheel electric vehicle drivers at intersections. Legal Medicine, 45, 101696. 
International Journal of Mathematical, Engineering and Management Sciences

Vol. 6, No. 3, 847-859, 2021

https://doi.org/10.33889/IJMEMS.2021.6.3.050

Zhgulev, E., Bozhuk, S., Evdokimov, K., \& Pletneva, N. (2018). Analysis of barriers to promotion of electric cars on Russian market. In 17th International Scientific Conference Engineering for Rural Development (pp. 2110-2117). Jelgava, Latvia. 